\title{
KẾT QUẢ ĐIỀU TRỊ PHẪU THUÂT GÃY ĐẦU DƯỚI HAI XƯƠ'NG CẲNG CHÂN BẰNG KỸ் THUÂT ÍT XÂM LẤN TẠI BỆNH VIỆN TRUNG ƯƠNG THÁI NGUYÊN
}

\author{
Nguyễn Thế Anh*, Nguyễn Quốc Huy*, Nguyễn Văn Sửu* \\ Hoàng Văn Dung**, Nguyễn Ngọc Sơn**
}

\section{TÓM TẮT}

Muc tiêu: Đánh giá kết quả điều trị phẫu thuật gãy đẩu dưới hai xương cẳng chân bằng kỹ thuật ít xâm lấn tại bệnh viện Trung ương Thái Nguyên. Đối tượng và phương pháp: Nghiên cứu tiến cứu, mô tả cắt ngang 31 bênh nhân gãy đâuu dưới hai xương cẳng chân được kết hợp xương nẹp vít ít xâm lấn (MIPO: Minimal invassive plate osteosynthesis). Kết quả: Nguyên nhân chấn thương chủ yếu là do tai nạn giao thông 70,97\%. Phân loại theo AO: gãy loại Ȧ1 $54,84 \%$, gãy loại $A 225,81 \%$ và gãy loại $A 319,35 \%$. Thời gian nằm viện trung bình là $7,13 \pm 1,76$ ngày. Kết quả nắn chỉnh giải phẫu theo tiêu chuân của Larson và Bostman tốt và rất tốt với tỉ lệ là $83,87 \%$, trung bình chiếm 16,13\%. Kết quả liền xương theo tiêu chuẩn của JL Haas và JY De La Cafinière: xương liền tốt và rất tốt chiếm $83,87 \%$, liền xương trung bình chiếm $16,13 \%$. Thời gian liền xương trung bình 19,3 tuần. Kết quả phục hồi chức năng theo thang điểm AOFAS tốt và rất tốt chiếm tỉ lệ $87,1 \%$, trung bình chiếm tỉ lê $12,9 \%$, không có kết quá phục hồi kém. Kết quả chung: tốt và rất tốt chiếm tỉ lệ cao $87,1 \%$, trung bình chiếm tỉ lê $12,9 \%$. Kết luận: MIPO là phương pháp điều trị tốt đối với gãy đầu dưới xương chày, làm giảm tổn thương phân mềm trong phẫu thuât.

Tư khoá: Kết hợp xương bằng nẹp vít ít xâm lẩn, đầu dưới xương chày, nẹp khoá.

\section{SUMMARY \\ RESULTS OF TREATMENT DISTAL TIBIAL FRACTURE BY MINIMALLY INVASIVE PLATE OSTEOSYNTHESIS AT THAI NGUYEN NATIONAL HOSPITAL}

Objective: Result evaluation of treatment distal tibial fracture by minimally invasive plate osteosynthesis. Subject and method: A cohort study 31 patients with distal limb fracture were performed by minimally invasive plate osteosynthesis. Results: The cause of the injury is mainly due to traffic accident $70,97 \%$. According to AO classification: $54,84 \%$ type A1 fracture, $25,81 \%$ type A2 fracture and 19,35\% type A3 fracture. The average time in hospital was 7,13 $\pm 1,76$ days. According to Larson and Bostman classification: very good and good at $83,87 \%$, regular $16,13 \%$. JL Haas and JY De

\footnotetext{
*Trường Đại học Y Dược Thái Nguyên

**Bệnh viện Trung Ương Thái Nguyên

Chịu trách nhiệm chính: Nguyễn Thế Anh

Email: bs.nguyentheanh.dhyktn@gmail.com

Ngày nhận bài: 4.3.2021

Ngày phản biện khoa học: 23.4.2021

Ngày duyệt bài: 5.5.2021
}

La Cafinière classification:very good and good union $83,87 \%$ regular $16,13 \%$. Time averaged union is 19,3 weeks. AOFAS results were excellent and good at 87,1 $\%$. Overall results: Excellent and good accounted for $87,1 \%$, regular $12,9 \%$. Conclusion: MIPO is an effective method of treatment for distal tibia fractures, decreases surgical trauma to soft tissues.

Keywords: MIPO, distal tibial, locking plate

\section{I. ĐĂT VẤN ĐỀ}

Gãy đâuu dưới hai xương cẳng chân là thương tổn thường gặp, chiếm tỉ lệ 7- 10\% các thương tổn hai xương cẳng chân và luôn đặt ra những khó khăn, thách thức trong điều trị. Điều trị bảo tồn bằng nắn chỉnh kín, bó bột đã được Bohler đề xướng và thu được nhiều thành công với khung kéo nắn của Bohler, tạo ra sự chùng các khối cơ ở cẳng chân, nắn chỉnh để đạt được về mặt giải phẫu, sau đó bó bột. Tuy nhiên khi ổ gãy phức tạp, đường gãy chéo xoắn dễ di lệch thứ phát trong bột, nhất là sau khi hết phù nề. Điều trị phẫu thuật mở ổ gãy kết hợp xương bên trong, thường phải lấy bỏ khối máu tụ quanh ổ gãy và những mãnh xương vụn là những yếu tố góp phần hình thành can xương, gây tổn thương thêm phần mềm xung quanh, cũng như màng xương, làm tổn thương mạch máu nuôi xương. Do đó, nguy cơ chảy máu sau mổ, nguy cơ toác vết mổ, nhiếm trùng, chậm liền xương cao. Nắn chỉnh kín hoặc mở ổ gãy kết hợp xương bên ngoài bằng khung cố định ngoài có ưu điểm có thể cố định ổ gãy vững chắc và tạo liền xương kỳ đầu, tuy nhiên hay gặp biến chứng nhiễm trùng chân đinh và di lệch ổ gãy thứ phát do lỏng đinh, tỳ đè sớm. Đặc biệt vấn đề nhiễm trùng sau mổ đã gây không ít khó khăn trong điêu trị, nhất là khi viêm xương .

Nắn chỉnh kín và kết hợp xương bằng nẹp vít xâm lấn tối thiểu dưới màn hình tăng sáng (MIPO - Minimal invassive plate osteosynthesis) là phương pháp có nhiều ưu điểm. Phấu thuật viên chỉ rạch da tối thiểu, nắn chỉnh lại ổ gãy và luồn dụng cụ kết hợp xương. Do vậy, hạn chế tổn thương thêm da và tổ chức phần mềm dưới da cũng như xương và màng xương, khối máu tụ quanh ổ gãy và những mảnh xương vụn được giữ gần như nguyên vẹn, giúp cho sự liền xương nhanh, tập vận động sớm. 
Do vậy, chúng tôi tiến hành đề tài này với mục tiêu: Đánh giá kết quả điều trị phẫu thuật gã்y đầu dưới hai xương cẳng chân bằng kỹ thuật ít xâm lấn tại bệnh viện Trung ương Thái Nguyên.

II. ĐỐl TƯỢNG VÀ PHƯƠNG PHÁP NGHIÊN CỨU

1. Đối tượng: Gồm 31 bệnh nhân gãy đầu dưới hai xương cẳng chân được mổ kết hợp xương bằng nẹp khoá kỹ thuật ít xâm lấn (MIPO), được theo dõi và tái khám định kỳ tại Bệnh viện Trung ương Thái Nguyên từ năm 2016 đến 2018.

2. Tiêu chuẩn chọn bệnh nhân: Bệnh nhân gãy kín hoặc gãy hở độ I đầu dưới hai xương cẳng chân, gãy đơn thuần xương chày phân loại theo AO. Được khám lâm sàng, cận lâm sàng đầy đủ.

3. Tiêu chuẩn loại trừ: Những trường hợp gãy hai xương cẳng chân do bệnh lý. Những trường hợp gãy hở độ II, III theo phân độ Gustilo, bệnh nhân có tổn thương phần mềm nặng. Thông tin hồ sơ bệnh án không đầy đủ.

4. Phương pháp: Nghiên cứu mô tả cắt ngang không đối chứng.

+ Các bước phẫu thuật:

- Tư thế bệnh nhân: Bệnh nhân nằm ngửa trên bàn mổ

- Gãy xương mác có chỉ định mổ sẽ tiến hành làm nẹp vít xương mác trước.

- Gãy xương chày: Chuẩn bị nẹp vít khoá đầu xa xương chày, định vị nẹp trên da, rạch da ở vị trí đầu xa và đâu gần của nẹp theo đường trước trong xương chày, mỗi đường rạch khoảng 2-3 $\mathrm{cm}$, dùng dụng cự lóc mô dưới da và luồn nẹp.

- Nắn chỉnh trục xương và các mảnh gãy lớn bằng tay theo mặt phẳng trong ngoài

- Kiểm tra dưới C- arm xương chày mặt phẳng trong - ngoài và mặt phẳng trước - sau đến khi thẳng trục và chấp nhận được.

- Bắt 1 hoặc 2 vít đầu ngoại vi, sau đó bắt 1 vít đầu trung tâm.

- Kiểm tra lại ổ gãy trên C- arm.

- Bắt các vít còn lại.

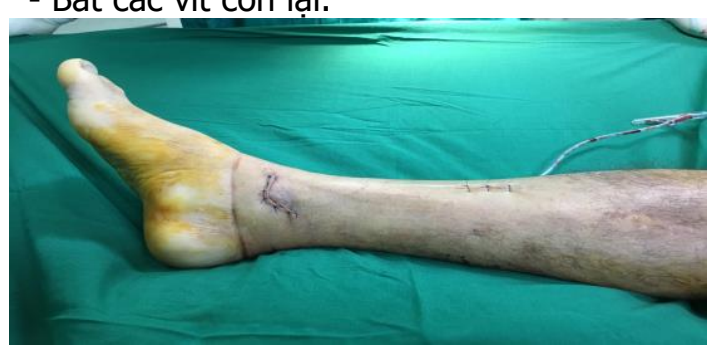

Hình 1. Luồn nẹp dưới da

+ Đánh giá sau mổ:

- Kết quả gần: Đánh gía tình trạng vết mổ, đánh giá kết quả nắn chỉnh ổ gãy dựa vào phim $X$ quang sau mổ theo tiêu chuẩn của Larson và Bostman.

- Kết quả xa: Thời gian liền xương dựa vào phim $X$ quang theo tiêu chuẩn của JL Haas và JY De La Cafinière, kết quả phục hồi chức năng (PHCN) theo thang điểm American Orthopaedic Foot and Ankle Score (AOFAS).

- Kết quả chung: Sẹo mổ, liền xương tại ổ gãy theo tiêu chuẩn đánh giá kết quả liền xương của JL Haas và JY De La Cafinière, biến chứng, tiêu chuẩn PHCN theo thang điểm AOFAS.

5. Xử lý số liệu: Phân tích số liệu bằng phần mềm thống kê y học STATA 10.0.

\section{KẾT QUẢ NGHIÊN CỨU}

Bảng 1. Phân bố bênh theo nhóm tuổi

\begin{tabular}{|c|c|c|}
\hline Nhóm tuổi & Số BN & Tỉ lệ (\%) \\
\hline $18-30$ & 15 & 48,39 \\
\hline $31-50$ & 11 & 35,48 \\
\hline$>50$ & 5 & 16,13 \\
\hline Tống số & $\mathbf{3 1}$ & $\mathbf{1 0 0}$ \\
\hline
\end{tabular}

Nhóm tuối 18-50 chiếm tỉ lề cao là 83,87\%, đây là độ tuổi lao động chính. Tuổi trung bình là $35,72 \pm 13,39$, lớn tuổi nhất là 63 , nhỏ tuổi nhất là 18 .

Bảng 2. Nguyên nhân gây tai nạn

\begin{tabular}{|c|c|c|}
\hline Nguyên nhân & $\begin{array}{c}\text { Số bệnh } \\
\text { nhẩn }\end{array}$ & Tỉ lệ \% \\
\hline Tai nạn giao thông & 22 & 70,97 \\
\hline Tai nạn sinh hoạt & 6 & 19,35 \\
\hline Khác & 3 & 9,68 \\
\hline Tống số & $\mathbf{3 1}$ & $\mathbf{1 0 0}$ \\
\hline
\end{tabular}

Nguyên nhân chủ yếu do tai nạn giao thông chiếm tỉ lệ 70,97\% các trường hợp.

\section{Bảng 3. Phân độ gãy xương theo AO}

\begin{tabular}{|c|c|c|}
\hline Mức độ & Số BN & Tỉ lệ(\%) \\
\hline Độ A1 & 17 & 54,84 \\
\hline Độ A2 & 8 & 25,81 \\
\hline Độ A3 & 6 & 19,35 \\
\hline Tống số & $\mathbf{3 1}$ & $\mathbf{1 0 0}$ \\
\hline
\end{tabular}

Gãy loại A1 chiếm tỉ lệ cao nhất 54,84\%.

+ Trong nghiên cứu của chúng tôi có 9 BN có gãy xương mác kèm theo trong đó có 4 ca gãy thấp gây mất vững khớp cổ chân nên được mổ kết xương bằng nẹp vít, $5 \mathrm{ca}$ còn lại gãy cao và di lệch ít nên chúng tôi không kết xương mà bất động thêm bằng nẹp bột cẳng bàn chân.

+ Thời gian nằm viện trung bình là $7,13 \pm 1,76$ ngày. Ngắn nhất là 6 ngày, dài nhất là 10 ngày.

+ Thời gian theo dối trung bình là 9,12 \pm 2,11 tháng

+ Tất cả các trường hợp đều không có nhiễm trùng vết mổ. 


Bảng 4. Kết quả nắn chỉnh ổ gãy theo
tiêuu chuân Larson và Bostman
\begin{tabular}{|c|c|c|}
\hline Kết quả & Số BN & Tỉ lệ(\%) \\
\hline Rất tốt & 18 & 58,06 \\
\hline Tốt & 8 & 25,81 \\
\hline
\end{tabular}

Bảng 5. Kêt quả liền xương theo độ gãy xương

\begin{tabular}{|c|c|c|c|c|c|c|c|}
\hline \multirow{3}{*}{ Độ gãy xương } & \multirow{2}{*}{\multicolumn{4}{|c|}{$\frac{\text { Kết quả liên xương }}{\text { Tốt }}$}} & \multirow{2}{*}{\multicolumn{2}{|c|}{ Trung binh }} & \multirow{3}{*}{ Tổng } \\
\hline & & & & & & & \\
\hline & BN & $\%$ & BN & $\%$ & BN & $\%$ & \\
\hline $\mathrm{A} 1$ & 17 & 54,84 & 0 & 0 & 0 & 0 & 17 \\
\hline A2 & 1 & 3,225 & 7 & 22,58 & 0 & 0 & 8 \\
\hline A3 & 0 & 0 & 1 & 3,225 & 5 & 16,13 & 6 \\
\hline Tống & 18 & 58,065 & 8 & 25,805 & 5 & 16,13 & $31(100 \%)$ \\
\hline
\end{tabular}

Liền xương kết quả tốt và rất tốt có 26 bênh nhân chiếm $83,87 \%$, chủ yếu trong nhóm gãy $A 1$ và $A 2$, liên xương trung bình có 5 bệnh nhân chiếm $16,13 \%$. Kết quả liền xương có sự khác biêt có ý nghĩa thống kê giữa loại gãy $A 3$ và 2 loại còn lại với $p<0,05$.

Bảng 6. Kêt quả PHCN theo thang điểm AOFAS

Kết quả tốt và rất tốt chiếm tỉ lệ cao $87,1 \%$, trung bình chiếm tỉ lệ 12,9 \%, không có kết quá phục hồi kém.

Bảng 7. Kết quả chung

\begin{tabular}{|c|c|c|}
\hline Kết quả & Số BN & Tỉ lệ (\%) \\
\hline Rất tốt & 18 & 58,06 \\
\hline Tốt & 9 & 29,04 \\
\hline Trung bình & 4 & 12,90 \\
\hline Tống & $\mathbf{3 1}$ & $\mathbf{1 0 0}$ \\
\hline
\end{tabular}

Kết quả tốt và rất tốt chiếm tỉ lệ cao $87,1 \%$, trung bình chiếm tỉ lệ 12,9\%.

\section{BÀN LUÂN}

1. Tuổi: Trong 31 bênh nhân nghiên cứu tuổi cao nhất là 63 , tuổi nhỏ nhất là 18 , tuổi trung bình là 35,72 . Trong đó nhóm bệnh nhân $18-50$ tuổi chiếm tỉ lê cao nhất $83,87 \%$. Theo nghiên cứu của Nguyễn Văn Trường tuổi trung bình là 41,6; nhóm 19- 45 tuổi chiếm 49,1\% [3]; và Trần Hoàng Tùng nhóm 16- 59 tuổi là $88,4 \%$ [5]. Nghiên cứu 79 bệnh nhân của Rakesh K. tuổi trung bình là 36 tuổi, nhóm tuổi 17- 58 chiếm đa số [7].

Như vậy kết quả nghiên cứu của chúng tôi cũng phù hợp với các nghiên cứu trên, chủ yếu ở độ tuổi lao động. Nhóm tuổi này đang trong độ tuổi học tập và lao động chính của xã hội nên

\begin{tabular}{|c|c|c|}
\hline Kết quả & Số BN & Tỉ lệ (\%) \\
\hline Rất tốt & 19 & 61,29 \\
\hline Tốt & 8 & 25,81 \\
\hline Trung bình & 4 & 12,90 \\
\hline Tống & $\mathbf{3 1}$ & $\mathbf{1 0 0}$ \\
\hline
\end{tabular}
việc điều trị phải sớm để nhanh chóng phục hồi

\begin{tabular}{|c|c|c|}
\hline Trung bình & 5 & 16,13 \\
\hline Tống & $\mathbf{3 1}$ & $\mathbf{1 0 0}$ \\
\hline \multicolumn{2}{|c|}{ Đa số các trường hợp được nắn chỉnh tốt và } \\
\hline
\end{tabular}
rất tốt với tỉ lệ là $83,87 \%$. Nắn chỉnh ở mức trung bình chiếm 16,13\%. cơ năng cho bệnh nhân và trả lại sức lao động cho ho.

2. Đặc điểm X quang: Phân loại gãy xương trong nghiên cứu dựa theo phân loại của $A O$. Tất cả bênh nhân trong nghiên cứu của chúng tôi đều là gãy loại $A$, là gãy đầu dưới hai xương cẳng chân ngoài khớp. có 17 bệnh nhân gãy loại A1 chiếm $54,84 \%, 8$ bênh nhân gãy loại $A 2$ chiếm 25,81\%, 6 bênh nhân gãy loại A3 chiếm $19,35 \%$. Theo nghiên cứu của Hoàng Thanh Hà có $16 \mathrm{BN}$ loại $A 1,4 B N$ loại $A 2,17$ loại $A 3$ và 1 loại C1 [1].

Theo Rakesh kỹ thuât MIPO nên áp dung với loại gãy ngoài khớp (loại $A$ ) hoặc đường gãy đơn thuần vào khớp, diện khớp không di lệch (loại B1, C1) [7]. Nhưng bên cạnh đó cũng có nhiều tác giả sử dụng kỹ thuật này cho gãy pham khớp di lệch nhiều: Cheng $W$ tiến hành trên 28 bệnh nhân, trong đó có gãy loại B2, B3, C3 phần lớn kết quả tốt, có 1 trường hợp gãy B2 chậm liền, 1ca khác gãy nep. Lau T. W nghiên cứu $48 \mathrm{BN}$ có $51 \%$ gãy loại A, 35\% loại B, $14 \%$ loại C kết quả tốt chiếm đa số [9].

\section{Kết quả gân:}

+Thời gian nằm viện trung bình là 7,13 $\pm 1,76$ ngày. Ngắn nhất là 6 ngày, dài nhất là 10 ngày. Theo Hoàng Thanh Hà thời gian nằm viện trung bình là 5,45 ngày (ngắn nhất 3 ngày, dài nhất 14 ngày) [1]. Các tác giả nước ngoài: Cheng W 2011 là 12,1 $\pm 3,7$ ngày [10]. Như vậy kết quả của chúng tôi phù hợp với tác giả trong nước, nhưng ngắn hơn so với các tác giả nước ngoài. Tuy nhiên trong nghiên cứu của các tác giả nước ngoài tiêu chuẩn chọn bệnh nhân rộng rãi hơn (gãy hở độ II, IIIA theo Gustilo và gãy loại $B, C$ theo $A O)$, nên điều này là phù hợp. Như vậy thời gian nằm viện ngắn là một trong những ưu điểm của phương pháp này.

+Tình trạng vết mổ: Trong nghiên cứu chúng tôi không gặp trường hợp nào nhiễm trùng sau 
mổ. Theo Hoàng Thanh Hà, nghiên cứu 38 BN không ca nào nhiễm trùng [1]. Trần Hoàng Tùng tỉ lệ nhiễm trùng nông là $7,89 \%$; nhiễm trùng sâu là $2,64 \%$ [5]. Các tác giả nước ngoài tỉ lệ nhiễm trùng tương đối thấp: Hazarika $S$ có $1 / 20$ trường hợp nhiễm trùng [8]. Lau T.W có $8 / 48$ trường hợp nhiễm trùng [9]. Rakesh K. Gupta nghiên cứu $80 \mathrm{BN}$ trong đó $71 \mathrm{BN}$ làm kỹ thuật MIPO có 1 trường hợp nhiễm trùng [10]. Điều này có thể hiểu được bởi điều kiện, trang bị y tế ở những nơi thực hiện nghiên cứu là rất tốt.

+ Kết quả nắn chỉnh: Sự nắn chỉnh xương gãy không tốt về mặt giải phẫu sẽ dẫn đến sự liền xương kém hơn, can lệch và ảnh hưởng xấu đến cơ năng của bệnh nhân như: viêm khớp, ngắn chi, đi lại khó khăn gây đau cho bệnh nhân. Bệnh nhân sau mổ được tiến hành chup Xquang để kiểm tra. Trong nghiên cứu của mình chúng tôi sử dụng tiêu chuẩn của Larson và Bostman để đánh giá kết quả phẫu thuật. Đa số các trường hợp được nắn chỉnh tôt và rất tốt với tỉ lệ là $83,87 \%$. Nắn chỉnh ở mức trung bình chiểm $16,13 \%$.

4. Kết quả xa: Chúng tôi khám lại bệnh nhân sau mổ trung bình là 9,12 tháng.

+ Kết quả liền xương: dựa theo bảng đánh giá của JL Haas và JY De La Cafiniere. Liền xương kết quả tốt và rất tốt có 26 bệnh nhân chiếm $83,87 \%$, chủ yếu trong nhóm gãy $A 1$ và $A 2$, liền xương trung bình có 5 bệnh nhân chiếm 16,13\%. Thời gian liên xương trung bình là 19,3 tuần. Theo Hoàng Thanh Hà, thời gian liền xương trung bình là 13,84 tuần (biến thiên 10-20 tuần) [1]. Tác giả Nguyễn Văn Trường nghiên cứu 46 BN gãy hở đầu xa cẳng chân bằng cố định ngoài thời gian liên xương trung bình là 22,8 tuần, trong đó $60,9 \%$ trường hợp liên xương rất tốt và tốt [3]. Trần Hoàng Tùng 31/38 BN liền xương sau khám lại 6 tháng [5]. Theo Collinge $38 / 38$ ca liền xương, liền xương trung bình 21 tuần (9- 48 tuần) [6]. Như vậy nghiên cứu của chúng tôi cũng phù hợp với nghiên cứu của các tác giả trong và ngoài nước. Điều này cho thây kỹ thuật MIPO cho kết quả liên xương sớm.

Theo bảng 5 ta thấy có sự khác biệt về kết quả liền xương giữa các loại gã̃y. Gãy loại $A 1, A 2$ có kết quả liền xương tốt chiếm đa số, loại gãy A3 kết quả liền xương trung bình chiếm tỉ lệ cao, sự khác biệt có ý nghĩa thống kê với $p<0,05$. Theo Michael W.Chapman gãy phức tạp tiên lượng về nắn chỉnh trong mổ khó hơn gãy đơn giản, đồng thời những loại gãy này làm đứt hoàn toàn hoăc phần lớn những mạch máu bên trong màng xương dẫn đến sự nuôi dưỡng ổ gãy kém hơn và dẫn đến chậm liền xương.

+ Kết quả phục hồi chức năng: Trong nghiên cứu này chúng tôi sử dụng thang điểm AOFAS để đánh giá kết quả PHCN. Kết quả tốt và rất tốt chiếm tỉ lệ cao $87,1 \%$, trung bình chiếm tỉ lệ 12,9 \%, không có kết quả phục hồi kém. Theo Trân Hoàng Tùng tỉ lệ tốt và rất tốt chiếm $94,74 \%$. Phan Văn Ngọc và CS tỉ lệ tốt và rất tốt là $90 \%$ [4]. Như vậy kết quả PHCN trong nghiên cứu của chúng tổi thấp hơn các nghiên cứu khác. Nguyên nhân là do trong 31 bệnh nhân có 5 trường hợp nắn chỉnh xương đạt mức trung bình sau mổ. Cũng có thể do những chấn thương vùng này gần khớp cổ chân nên trong quá trình tập luyện bệnh nhân đau nhiều kết hợp với sự hiểu biết của bệnh nhân còn ít về tập luyện nên chưa tích cực tập luyện khớp cổ chân. Tuy nhiên đây vẫn là một kết quả khả quan cho thây những ưu điểm của kỹ thuật ít xâm lấn.

+ Biến chứng: Trong 31 bệnh nhân của nhóm nghiên cứu không có trường hợp nào viêm xương, chậm liền xương, khớp giả, gãy nẹp vít. Kết quả tương tự như trong nghiên cứu của Hoàng Thanh Hà [1] và nhiều tác giả khác.

\section{KẾT LUẬN}

Qua nghiên cứu điều trị 31 bệnh nhân gãy đầu dưới hai xương cẳng chân bằng kết hợp xương nẹp vít ít xâm lấn (MIPO), chúng tôi thẩy: Tuổi trung bình $36,75 \pm 15,48$, nhóm tuổi 18 50 chiếm tỉ lệ cao $83,87 \%$. Nguyên nhân chấn thương chủ yếu là do tai nạn giao thông 70,97\%. Theo AO: Gãy loại $A 1$ chiếm tỉ lệ cao nhất $54,84 \%$.

Thời gian nằm viện trung bình là $7,13 \pm 1,76$ ngày, không có trường hợp nào nhiễm trùng. Kết quả nắn chỉnh giải phẫu theo tiêu chuẩn của Larson và Bostman Đa số các trường hợp được nắn chỉnh tốt và rất tốt với tỉ lệ là $83,87 \%$, trung bình chiếm $16,13 \%$. Kết quả liển xương theo tiêu chuẩn của JL Haas và JY De La Cafinière: Liền xương kết quả tốt và rất tốt có 26 bệnh nhân chiếm $83,87 \%$, chủ yếu trong nhóm gãy $A 1$ và $A 2$, liền xương trung bình có 5 bệnh nhân chiếm $16,13 \%$. Thời gian liền xương trung bình 19,3 tuần. Kết quả phục hồi chức năng theo thang điểm AOFAS kết quả tốt và rất tốt chiếm tỉ lệ cao $87,1 \%$, trung bình chiếm tỉ lệ $12,9 \%$, không có kết quả phục hồi kém.

\section{TÀI LIÊU THAM KHẢO}

1. Hoàng Thanh Hà, Trân Chí Khôi (2013), Đieều trị gãy đâuu dưới xương chày bằng nẹp vít, phẩu thuật ít xâm lấn, Tạp chí Hội nghị thưởng niên lần XX Hội CTCH Thành phố Hồ Chí Minh, tr. 81 - 83. 
2. Nguyễn Văn Nhân, Nguyễn Tiến Bình (2009), Điểu trị gãy hở và di chứng hai xương cằng chân, Nhà xữ̂́t bản $Y$ học.

3. Nguyễn Văn Trường (2012), Đánh giá kết quả điểu trị gãy hở đâu xa hai xương cẳng chân bằng cố định ngoài tại bệnh viện hữu nghi Việt Đức, Luân văn thac sĩ Y hơc, Đai học Y Hà Nối.

4. Phan Văn Ngọc và cs (2019), Điều trị gãy đầu dưới xương chày bằng kỹ thuât ít xâm lấn tai bênh viện Sài Gòn Ito Phú Nhuận, Tạp chí Chấn Thưởng Chỉnh Hình số đặc biệt, tr. 195- 203.

5. Trân Hoàng Tiùng (2006), Điều trị kết hợp xương nepp vít gãy kín hai xương cẳng chân bằng kĩ thuật ít xâm lấn, Luận văn tốt nghiệp bác sĩ nội trú, Đại học Y Hà Nội.
6. Collinge C, Protzman R (2010), Outcomes of minimally invasive plate osteosynthesis for metaphyseal distal tibia fractures, J Orthop Trauma. 24(1), pp. 4-9.

7. Rakesh K. Gupta et al (2010), Locking plate fixation in distal metaphyseal tibial fractures: series of 79 patients, Int Orthop. 34(8), pp. 85-90.

8. Hazarika S, Chakravarthy J, Cooper J (2006), Minimally invasive locking plate osteosynthesis for fractures of the distal tibia - results in 20 patients, Injury. 37(9), pp. 77-87.

9. Lau T. W (2008), Wound complication of minimally invasive plate osteosynthesis in distal tibia fractures, Int Orthop. 32(5), pp. 697-703.

\section{THAY ĐỔI THỂ TÍCH KHÍ LƯU THÔNG VÀ COMPLIAN PHỔI KHI HUY ĐộNG PHẾ NANG TRONG GÂY MÊ CHO PHẪU THUÂ̂T Ổ BỤNG TRÊN NGƯỜI CAO TUỔI}

\section{TÓM TẮT}

Mục tiêu: Đánh giá thay đổi thể tích khí lưu thông và complian khi huy động phế nang trong phẫu thuật ổ bụng trên người cao tuổi. Đối tượng và phương pháp: Nghiên cứu can thiệp lâm sàng. Chọn bệnh nhân có ASA $1-3$, tuổi $\geq 60$, được gây mê nội khí quản để phẫu thuật ổ bụng. Bệnh nhân được chia làm 2 nhóm, nhóm chứng 37 bênh nhân thở máy với PEEP $+5 \mathrm{CmH}_{2} \mathrm{O}$, nhóm can thiệp 45 bệnh nhân được huy động phế nang với áp lực $+40 \mathrm{CmH}_{2} \mathrm{O}$ và duy trì $\mathrm{PEEP}+5 \mathrm{CmH}_{2} \mathrm{O}$. Cả hai nhóm được đánh giá sự thay đổi về thể tích khí lưu thông và độ giãn nở phổi trong quá trình gây mê. Kết quả: Thể tích khí lưu thông và độ đàn hồi phổi sau khi huy động phế nang cao hơn so với trước khi huy động $(p<0,05)$. Nhóm huy động phế nang trước khi rút ống nội khí quản có Tv là

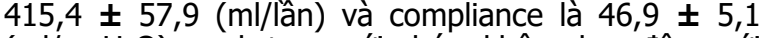
$\left(\mathrm{ml} / \mathrm{cmH}_{2} \mathrm{O}\right)$ cao hơn so với nhóm không huy động với Tv là 390,43 \pm 73,26 (ml/lần) và Compliance là 43,8 $\pm 4,8\left(\mathrm{ml} / \mathrm{cmH}_{2} \mathrm{O}\right)$. Kết luận: Huy động phế nang bằng áp lực $+40 \mathrm{cmH}_{2} \mathrm{O}$ giúp cải thiện chỉ số thể tích khí lưu thổng và độ đàn hồi phổi trển bệnh nhân cao tuổi được gây mê nội khí quản cho phẫu thuật ổ bụng.

Từ khóa: Huy động phế nang, phẫu thuật ổ bụng, gây mê người cao tuổi.

\section{SUMMARY \\ EVALUATION OF TIDAL VOLUME AND COMPLIANCE FOR ALVEOLAR}

\section{*Bênhh viện Hữu Nghi}

Chịu trách nhiệm chính: Công Quyết Thắng

Email: vnanesth@gmail.com

Ngày nhận bài: 5.3.2021

Ngày phản biên khoa họ: 22.4.2021

Ngày duyệt bài: 29.4.2021
Lại Văn Hoàn*, Công Quyết Thắng*, Lê Sáu Nguyên*, Nguyễn Thị Kim Oanh*.

\section{RECRUITMENT MANEUVERS DURING GENERAL ANESTHESIA FOR ABDOMINAL} SURGERY IN THE ELDERLY

Objective: Evaluate tidal volume and compliance for alveolar recruitment maneuvers undergoing general anesthesia for abdominal surgery in elderly. Subjects and Methods: A randomised controlled trials. Select patients with ASA $1-3$, age $\geq 60$ years, undergoing anesthesia for abdominal surgery. Control group enrolled 37 patients with PEEP $+5 \mathrm{CmH}_{2} \mathrm{O}$, the intervention group enrolled 45 patients maneuver consisted to a peak inspiratory pressure of $40 \mathrm{cmH}_{2} \mathrm{O}$ for 40 s one hours and PEEP $+5 \mathrm{CmH}_{2} \mathrm{O}$. Both groups were evaluated of tidal volume and compliance during anesthesia. Results: Tidal volume and compliance after alveolar mobilization were higher than before mobilization ( $p<0.05)$. The intervention before extubation with Tv was $415.4 \pm 57.9$ (ml/time) and compliance was $46.9 \pm 5.1(\mathrm{ml} / \mathrm{cmH} 2 \mathrm{O})$, higher than the control group with Tv is $390.43 \pm 73.26$ (ml/time) and Compliance is $43.8 \pm 4.8 \quad\left(\mathrm{ml} / \mathrm{cmH}_{2} \mathrm{O}\right)$. Conclusions: Alveolar recruitment maneuvers with pressure $+40 \mathrm{cmH}_{2} \mathrm{O}$ improves the Tidal volume and Compliance in elderly patients undergoing anesthesia for abdominal surgery.

Keywords: Alveolar mobilization, abdominal surgery, anesthesia for elderly.

\section{I. ĐĂT VẤN ĐỀ}

Trên thế giới nói chung và Việt Nam nói riêng phẫu thuật trên người cao tuổi ngày càng tăng. Có nhiều phương pháp vô cảm trong phẫu thuâtt, tuy nhiên phương pháp gây mê nội khí quản vần được lựa chọn cho các phẩu thuật lớn, can thiệp vào nhiều tổ chức có thời gian phẫu thuật kéo dài như phẫu thuật lớn vào ổ bụng... [2] Việc 